\title{
PENERAPAN E-COMMERCE MENGGUNAKAN METODE EXTREME PROGRAMMING PADA UMKM KABUPATEN MURATARA
}

\author{
Wisdalia Maya Sari ${ }^{1}$, Ali Amran ${ }^{2}$,Harma Oktafia Lingga Wijaya ${ }^{* 3}$ \\ Program Studi Informatika ${ }^{1,2}$, SistemInformasi ${ }^{3}$ Universitas Bina Insan Lubuklinggau \\ e-mail: ${ }^{1}$ wisdaliamayasari@ univbinainsan.ac.id, ${ }^{2}$ ali_amran85@gmail.com, \\ ${ }^{3}$ harmaoktafialingga@ univbinainsan.ac.id
}

\begin{abstract}
Abstrak
Metode Agile merupakan salah satu bentuk pendekatan metode pengembangan sistem yang berkembang saat ini untuk pemodelan perangkat lunak yang mengutamakan fleksibilitas dan kedinamisan setiap prosesnya terhadap perubahan-perubahan yang terjadi, dimana perubahanperubahan tersebut dapat dilakukan pada setiap tahapan proses yang ada. Salah satu metode Agile yang ada adalah pendekatan Extreme Programming (Extreme Programming Approach). Perbedaan Extreme Programming Approach (XP) dibandingkan dengan metode lainnya yaitu tidak memiliki dokumentasi secara formal dalam setiap tahapan proses konstruksinya. Adapun tahapan-tahapan yang harus dilalui dalam XP Approach antara lain: Tahapan explorasi, perencanaan, iterasi pengembangan sistem, dan tahapan akhir. Keunggulan dari XP Approach ini adalah perancangan perangkat lunak yang dilakukan tidak akan diubah, hanya sistem yang sedang dibangun saja yang berubah, dengan kata lain XP Approach memungkinkan tidak adanya dokumentasi formal yang dapat digunakan sebagai alat ukur bahwa aplikasi telah selesai dibangun, namun aplikasi dikatakan telah selesai apabila klien tidak melakukan penambahan analisis kebutuhan (requirement) pada aplikasi. Penambahan atau perubahan requirement ini tidak dibatasi, sehingga apapun keinginan klien akan dipenuhi. Melalui pendekatan XP ini akan dibangun sebuah aplikasi yang diperuntukkan untuk sistem penjualan berbasis online $(E$ commerce) dengan prinsip business to customer (B2C). E-commerce ini diperuntukkan bagi penjual khususnya yang bergerak di bidang UMKM pada wilayah Kabupaten Musirawas Utara yang ingin mengembangkan kegiatan jual beli barang dagangan kepada customer secara online.
\end{abstract}

Kata kunci : E-Commerce; Extreme Programming; UMKM

\begin{abstract}
The Agile method is a form of system development approach that is currently developing for software modeling that prioritizes the flexibility and dynamism of each process to the changes that occur, where these changes can be carried out at every stage of the existing process. One of the existing Agile methods is the Extreme Programming approach (Extreme Programming Approach). The difference between the Extreme Programming Approach (XP) compared to other methods is that it does not have formal documentation at each stage of the construction process. The stages that must be passed in the XP Approach include: Exploration stages, planning, system development iterations, and the final stage. The advantage of this XP Approach is that the software design that is carried out will not be changed, only the system being built has changed, in other words the XP Approach allows no formal documentation that can be used as a measuring tool that the application has been completed, but the application is said to have complete if the client does not add requirements analysis to the application. Additions or changes to these requirements are not limited, so whatever the client's wishes will be fulfilled. Through this XP approach an application will be built for online-based sales systems (E-commerce) with business to customer (B2C) principles. This e-commerce is intended for sellers, especially those engaged in the MSME sector in the North Musirawas Regency area who want to develop online trading activities of merchandise to customers.
\end{abstract}

Keywords : E-Commerce; Extreme Programming; UMKM 


\section{PENDAHULUAN}

Perkembangan dan kemajuan bisnis tidak luput dari adanya teknologi informasi, dengan kemajuanteknologi informasi yang sangat pesat dapatmemberikan kemudahan dalam mencari suatuinformasi sesuai apa yang di inginkan. Teknologiinformasi sangat dibutuhkan oleh sebuah instansiatau perusahaan untuk menunjang efesiensi danefektifitas dalam mengelola data agar didapatnyainformasi yang dibutuhkan. Dalam duniabisnis marak denganmunculnyasuatuistilahElectronic Commerce (E-Commerce). E-Commerce adalah proses membeli dan menjual produk-produk secara elektronik oleh konsumen dan dari perusahaan ke perusahaan dengan komputer sebagai perantara transaksi bisnis[1]. Media yang dapat digunakan dalam aktivitas $e$ commerce adalah World Wide Web internet [2], [3], [4], [5], [6], [7]. Dalam mengembangkan sebuah usaha para pemilik usaha ingin produk yang mereka miliki dijangkau oleh banyak konsumen.

Dalam mengembangkan suatu aplikasi berbasis web, tentunya dibutuhkan suatu pemodelan sistem yang menjadi acuan ataupun kerangka kerja dalam pengembangan sistemnya. Metode Agile merupakan salah satu bentuk pendekatan metode pengembangan sistem yang berkembang saat ini untuk pemodelan perangkat lunak yang mengutamakan fleksibilitas dan kedinamisan setiap prosesnya terhadap perubahan-perubahan yang terjadi, dimana perubahan-perubahan tersebut dapat dilakukan pada setiap tahapan proses yang ada. Salah satu metode Agile yang ada adalah pendekatan Extreme Programming (Extreme Programming Approach)[8]. Perbedaan Extreme Programming Approach (XP) dibandingkan dengan metode lainnya yaitu tidak memiliki dokumentasi secara formal dalam setiap tahapan proses konstruksinya. Adapun tahapan-tahapan yang harus dilalui dalam XP Approach antara lain: Tahapan explorasi, perencanaan, iterasi pengembangan sistem, dan tahapan akhir. Keunggulan dari XP Approach ini adalah perancangan perangkat lunak yang dilakukan tidak akan diubah, hanya sistem yang sedang dibangun saja yang berubah, dengan kata lain XP Approach memungkinkan tidak adanya dokumentasi formal yang dapat digunakan sebagai alat ukur bahwa aplikasi telah selesai dibangun, namun aplikasi dikatakan telah selesai apabila klien tidak melakukan penambahan analisis kebutuhan (requirement) pada aplikasi. Penambahan atau perubahan requirement ini tidak dibatasi,sehingga apapun keinginan klien akan dipenuhi. Melalui pendekatan XP ini akan dibangun sebuah aplikasi yang diperuntukkan untuk sistem penjualan berbasis online (Ecommerce) dengan prinsip business to customer (B2C). E-commerce ini diperuntukkan bagi penjual khususnya yang bergerak di bidang UMKM di kabupaten Musirawas Utara yang ingin mengembangkan kegiatan jual beli barang dagangan kepada customer secara online.

\section{TINJAUAN PUSTAKA}

\subsection{State of the Art}

Dalam penelitian [1], menyajian suatu kerangka kerja dalam perancangan aplikasi E-commerce yang diperuntukkan komoditas hasil pertanian. Adapun konstruksi pengembangan sistem yang digunakan antara lain: identifikasi kebutuhan, pengembangan sistem, membangun aplikasi, dan melakukan pengujian serta melakukan implementasi sistem. Kelemahan dari kerangka kerja dalam penelitian ini adalah tidak adanya feedback terhadap klien dalam melakukan penambahan fitur aplikasi dikarenakan kebutuhan terhadap sistem telah 
terdokumentasi ditahapan identifikasi kebutuhan. Berbeda dalam penelitian [3], peneliti menambahkan teknologi Virtual Reality dalam merancang aplikasi $E$ Commerce penjualan rumah. Dalam penelitian [5], peneliti menggunakan frame work web engineering dalam merancang aplikasi e-commerce untuk menunjang pemasaran produk pet shop. Dalam penelitian [9], [10], menyajikan suatu pendekatan object oriented dalam membangun suatu aplikasi e-commerce penjualan komoditas pakaian jadi di Distro Dlapak Street Wear. Kelemahan dari aplikasi yang dirancang yaitu tidak menyajikan feedback terhadap klien dalam melakukan penambahan fitur dikarenakan kebutuhan terhadap sistem telah terdokumentasi di tahapan identifikasi kebutuhan. Dalam penelitian [3], [4], [7], [11], menyajikan suatu kerangka kerja dengan menggunakan metode waterfall dalam perancangan aplikasi e-commerce yang diperuntukkan komiditas makanan ringan di Business Development Center Kabupaten Pringsewu. Kelemahan dalam metode waterfall ini setiap perubahan terhadap klien harus terdokumentasi pada setiap masing-masing tahapan sehingga developer harus mengulang tahapan dari awal proses.

Dari beberapa penelitian diatas, peneliti menawarkan suatu konsep perancangan perangkat lunak yang fleksibel dengan menggunakan Extreme Programming Approach dimana untuk dapat mengatasi kelemahan-kelemahan penelitian sebelumnya. Keunggulan dari $X P$ Approach ini adalah perancangan perangkat lunak yang dilakukan tidak akan diubah, hanya sistem yang sedang dibangun saja yang berubah, dengan kata lain $X P$ Approach memungkinkan tidak adanya dokumentasi formal yang dapat digunakan sebagai alat ukur bahwa aplikasi telah selesai dibangun, namun aplikasi dikatakan telah selesai apabila klien tidak melakukan penambahan analisis kebutuhan (requirement) pada aplikasi.

\subsection{Extreme Programming Approach}

Extreme Programming Approach pertama kali dikemukakan oleh Kent Beck, seorang pakar software engineering yang bekerja dengan Chrysler yang membuat proyek C3 (Chrysler Comperhensive Compensation). Pada saat itu proyek Chrysler terancam gagal sebelum Kent Beck dikontrak, kemudian saat Kent Beck memegang proyek ini, Kent Beck bersama Ron Jeffries menyelesaikan proyek sesuai dengan target dengan menggunakan berbagai metode, kemudian kumpulan metode ini disebut dengan metode XP. Kent Beck membuat perubahan pada pembangunan proyek dengan membuatnya lebih efisien, adaptif, dan fleksibel [8].

XP memiliki 4 nilai dasar yang menjadi inti pokok metode XP yaitu: Communication (Komunikasi), Simplicity (Kesederhanaan), Feedback (Umpan Balik), dan Courage (Keberanian). Keempat nilai dasar ini menunjukan bahwa XP bersifat fleksibel terhadap perubahan-perubahan yang diminta oleh klien.

Adapun tahapan dalam pembangunan aplikasi e-commerce dengan XP adalah sebagai berikut:

1) Tahap Eksplorasi

Tahapan eksplorasi adalah tahapan dimana klien menuliskan kebutuhankebutuhan darisistem yang paling mendasar. Setiap kebutuhan yang dituliskan oleh klien akan dibuatdalam bentuk modul yang sederhana atau disebut juga dengan User Stories. hasil daritahapan eksplorasi adalah mengetahui dokumentasi atas visi dan ruang lingkup pekerjaan.

2) Tahap Perencanaan

Tahapan perencanaan berorientasi kepada tahapan eksplorasi. Tahapan ini akanmemperkirakan kebutuhan bisnis, 
kebutuhan user, dan kebutuhan sistem.

Tahapan ini jugaakan menghasilkan penjadwalan yang menggambarkan perencanaan waktu pelaksanaanpembangunan sistem.

3) Iterasi Pengembangan Sistem

Pada tahapan ini, akan terjadi beberapa kali iterasi, setiap iterasi terdiri dari 3 tahapan yaituanalisis sistem, desain sistem, dan pembuatan dan pengujian sistem.

4) Tahap Produksi Akhir

Tahapan produksi akhir adalah tahapan dimana sistem sudah siap untuk di release. Tahapan ini akan melakukan testing terhadap keseluruhan sistem yang telah dibuat kepada klien.

\section{METODOLOGI PENELITIAN}

Extreme Programming Approach terdiri dari 4 tahapan perancangan utama, yaitu planning, design, coding, dan testing. Gambar 1 menunjukkan alur proses dari XP approach.

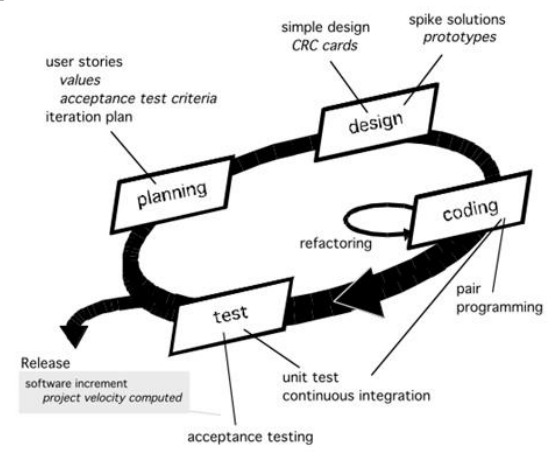

Gambar 1. XP Process

\subsection{Planning}

1 Tahap Eksplorasi

Merupakan tahapan awal dari pendekatan XP, pada tahapan ini, peneliti melakukan eksplorasi kebutuhan user yang dijabarkan dengan menggunakan User Stories (US). US dideskripsikan berdasarkan hasil dari interview kepada klien. Tabel 1 menyajikan user stories dari sistem yang akan dirancang
Tabel 1. User Stories

\begin{tabular}{|c|c|c|}
\hline $\mathbf{N}$ & User & Kebutuhan Sistem \\
\hline 1 & Admin & $\begin{array}{ll}\text { - Melakukan login } & \\
\text { Mengelola/ } & \\
\text { memanipulasi (insert, } \\
\text { update, dan delete) } \\
\text { seluruh content dan } \\
\text { informasi yang akan } \\
\text { ditampilkan } & \text { pada } \\
\text { halaman website. } & \end{array}$ \\
\hline 2 & Member & 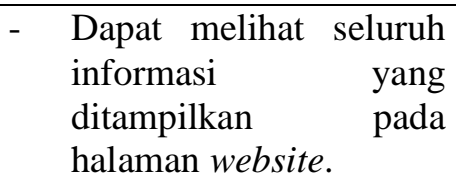 \\
\hline 3 & Guest & $\begin{array}{l}\text { Melihat fitur dan } \\
\text { melakukan registrasi }\end{array}$ \\
\hline
\end{tabular}

2 Tahap Perencanaan

Pada tahap perencanaan ini, akan dihasilkan kebutuhan bisnis, dan kebutuhan sistem, dengan mengacu kepada tahapan sebelumnya, yakni tahap eksplorasi.

\section{Kebutuhan Bisnis}

Kebutuhan bisnis dibagi menjadi dua bagian, yaitu kebutuhan perangkat keras dan kebutuhan perangkat lunak. Kebutuhan Sistem.

\section{Kebutuhan sistem}

Kebutuhan sistem adalah analisis yang dilakukan terhadap fungsionalitas sistem sertaperancangan data. Gambar 2 menyajikan use case diagram dari sistem yang akan dirancang.

\subsection{Design}

Pada tahapan desain, dilakukan pemodelan sistem berdasarkan hasil dari analisis kebutuhan. Desain sistem ini dalam perancangannya nanti bersifat fleksibel dan dinamis disesuaikan dengan masukanmasukan dari klien 


\section{Pembuatan Kode Program}

Pada proses ini, peneliti melakukan kegiatan pembuatan kode program (coding), untuk membuat program atau aplikasi yang sesuai dengan desain sistem sebelumnya.

2 Pengujian sistem

Kegiatan pengujian program dilakukan untuk melihat apakah system atau aplikasi yang dibuat masih terdapat kesalahan baik alur dan logika pemrogramannya serta untuk melihat apakah fungsi-fungsi ada dalam sistem berjalan sebagai mana mestinya.

\section{HASIL DAN PEMBAHASAN}

Kabupaten Musi Rawas Utara bertujuan untuk terciptanya sebuah sistem pemasaran dan pejualan produk UMKM yang berbasis teknologi informasi. Sistem ini terdiri dari dua user utama, yaitu: admin dan Pengguna (pelaku UMKM).

\subsection{Desain Antar Muka}

1 Halaman Login

Menu login digunakan oleh admin untuk masuk ke halaman utama user. Untuk masuk ke menu utama dibutuhkan akses login dengan memasukkan username dan password. Gambar 2 menunjukkan tampilan layout menu login admin.

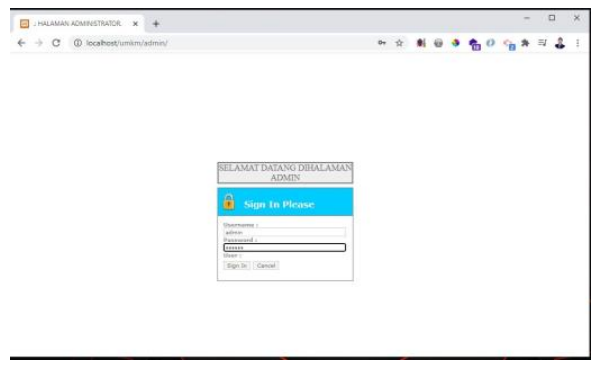

Gambar 2. Tampilan Halaman Login

\section{Halaman Menu Utama}

Setelah admin memasukkan username dan password dengan benar, maka sistem akan menampilkan halaman utama admin. Gambar 3 menunjukkan tampilan layout menu halaman utama.

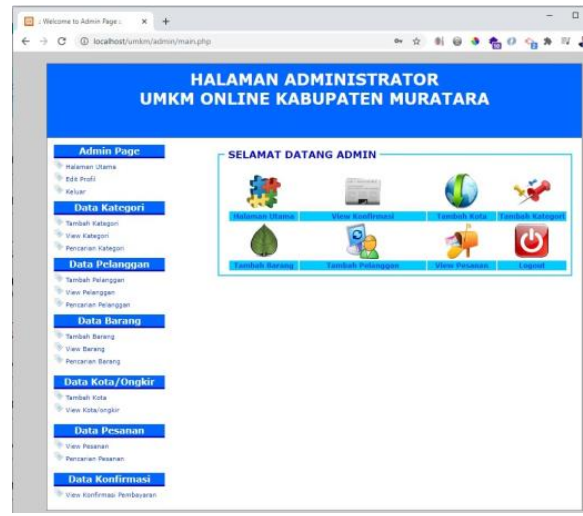

Gambar 3. Tampilan Halaman Utama

\section{Halaman Menu Kategori UMKM}

Menu halaman digunakan admin untuk melakukan penginputan data Kategori UMKM. Admin dapat melakukan tambah data, edit data, dan delete data. Gambar 4 menunjukkan tampilan layout menu halaman data Kategori UMKM.

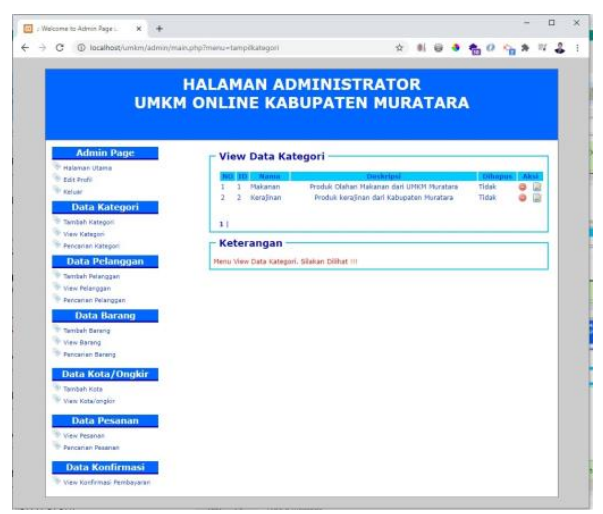

Gambar 4. Tampilan Menu Kategori UMKM

\section{Halaman Menu Data Barang}

Menu data barang digunakan admin untuk melakukan penginputan data barang. Admin dapat melakukan tambah data, edit data, dan delete data. Gambar 5 menunjukkan tampilan layout menu halaman data wilayah. 


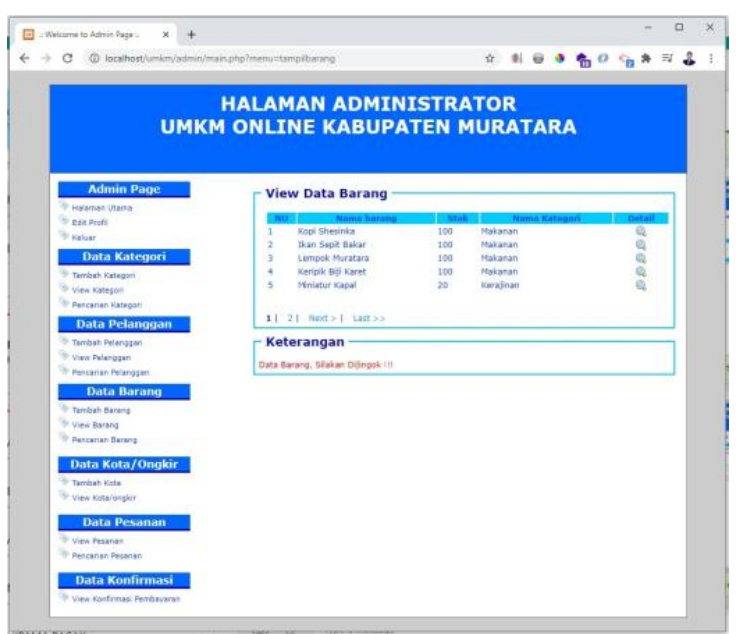

Gambar 5. Halaman Menu Data Barang

5 Halaman Menu Data Pelanggan dan Pemesanan

Menu Data pelanggan dan Pesanan digunakan oleh admin untuk melihat data pelanggan dan pesanan dalam sistem. Menu pelanggan digunakan untuk melakukan pencarianpelanggan. Gambar 6 menunjukkan tampilan layout menu data Pelanggan.

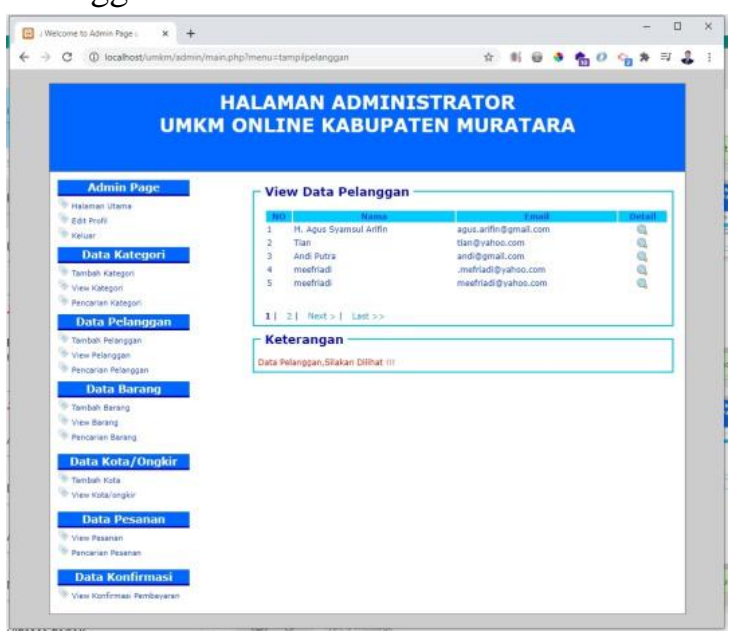

Gambar 6. Halaman Menu Halaman Data Pelanggan
6 Halaman Data Pesanan

Halaman data pesanan digunakan pelanggan untuk melakukan pemesanan terhadap produk UMKM yang ada. Gambar 7 menampilkan tampilan menu data pesanan.

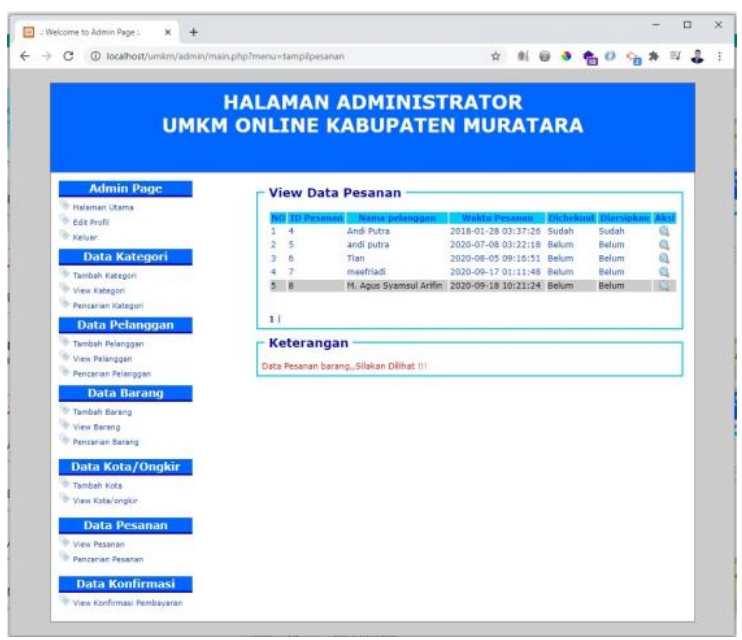

Gambar 7. Tampilan Menu Data Pesanan

7 Halaman Menu Detail Pemesanan

Halaman menu detail pemesanan menampilkan data pemesanan.Gambar 8 menampilkan detail pemesanan.

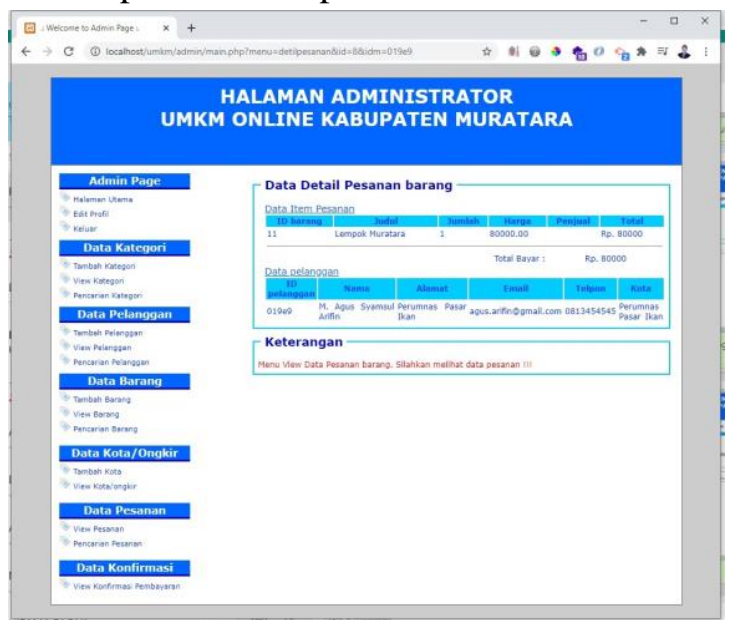

Gambar 8. Halaman Menu Detail Pemesanan 
8 Halaman Konfirmasi Pemesanan

Halaman konfirmasi pemesanan menampilkan bukti pembayaran yang telah dilakukan oleh pembeli. Gambar 9 menampilkan konfirmasi pemesanan.

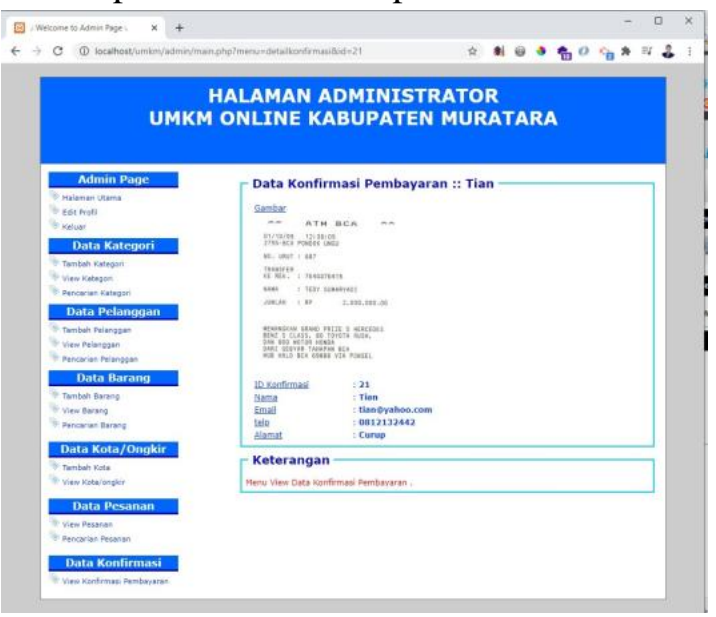

Gambar 9. Dashboard kepuasan pengguna

9 Halaman Pendaftaran Member

Halaman member menampilkan halaman untuk registrasi member. Gambar 10 menampilkan halaman member.

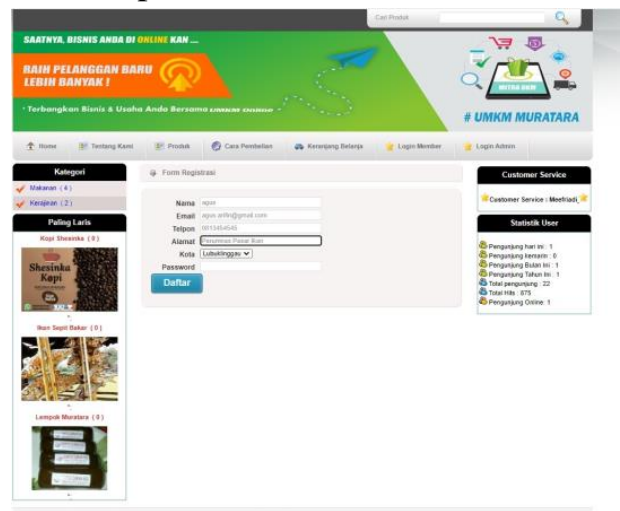

Gambar 10. Halaman Registrasi Member

10 Halaman Login Member

Halaman login member menampilkan login agar member bisa masuk kedalam sistem. Gambar 11 menampilkan halaman login member.

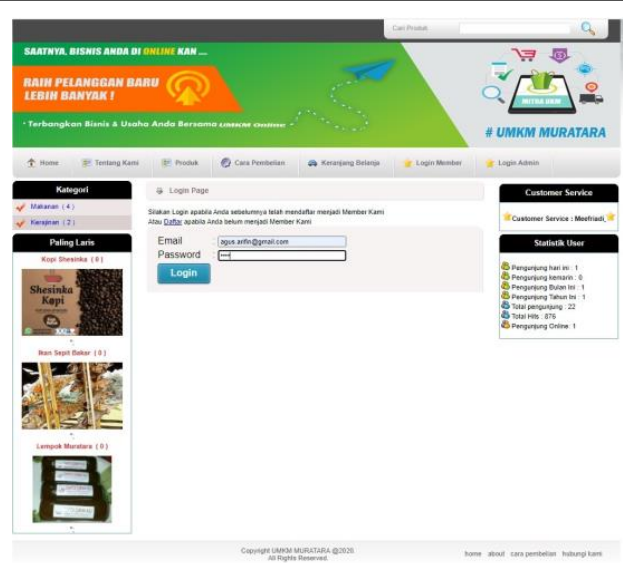

Gambar 11. Halaman Login Member

\section{Halaman Home Member}

Halaman home member menampilkan menu utama member. Gambar 12 menampilkan halaman home member.

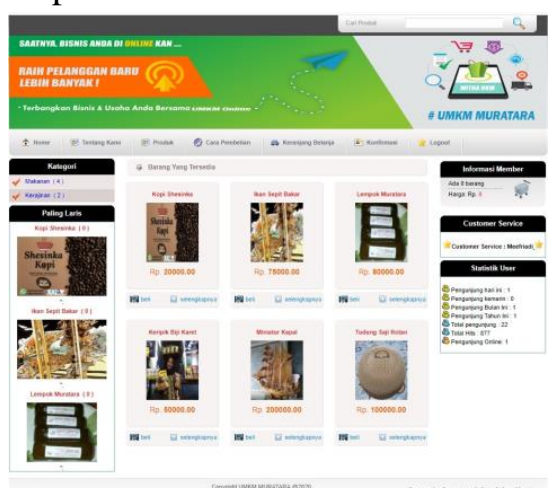

Gambar 12. Halaman Home Member

12 Halaman Keranjang Belanja Member Halaman keranjang belanja member menampilkan item belanja yang dilakukan oleh member. Gambar 13 Menampilkan Keranjang Belanja Member.

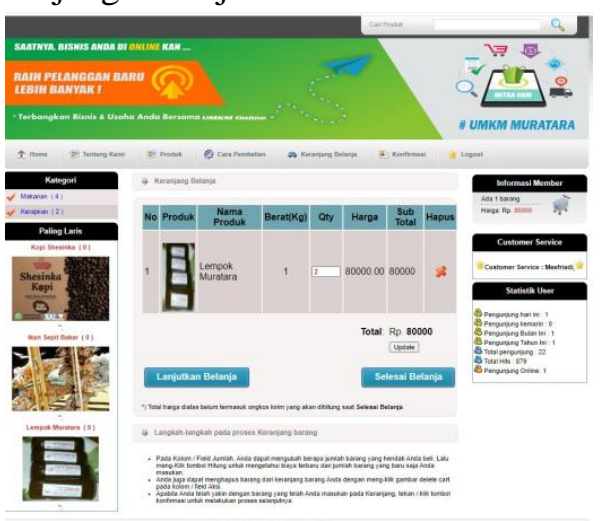

Gambar 13. Halaman Keranjang Belanja Member 
13 Halaman Checkout Belanja

Halaman checkout belanja meanmpilkan list dari daftar belanja yang akan dibeli. Gambar 14 Menampilkan checkout Belanja.

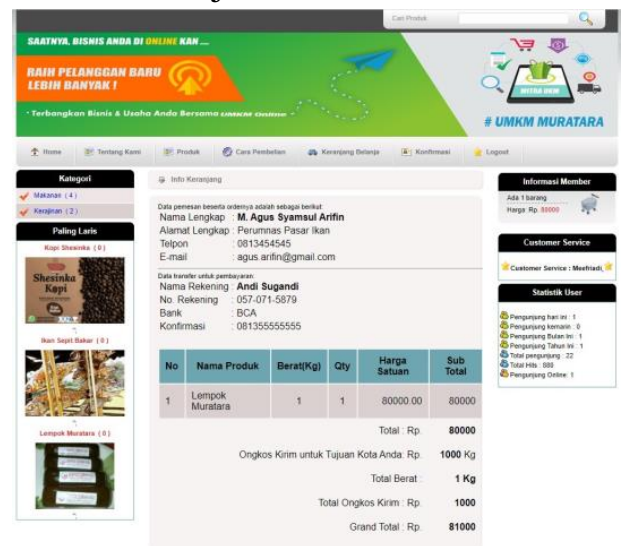

Gambar 14. Halaman Checkout Belanja

14 Halaman Konfirmasi Pembayaran

Halaman konfirmasi pembayaran digunakan oleh member untuk mengupload bukti pembayaran. Gambar 15 Menampilkan konfirmasi.

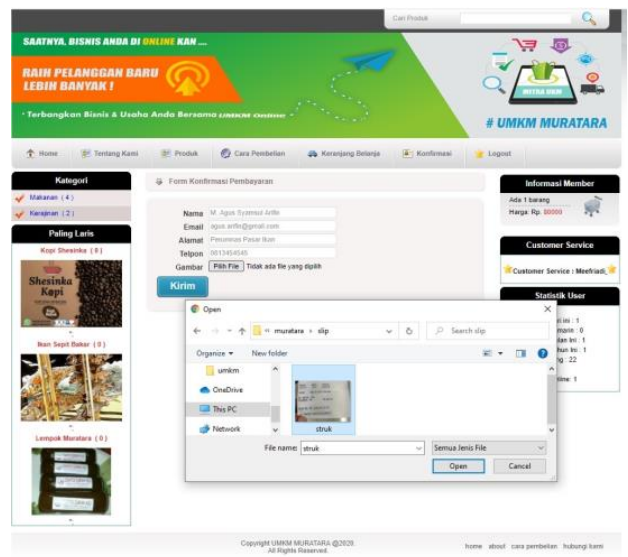

Gambar 15. Halaman Konfirmasi Pembayaran

\section{KESIMPULAN}

Berdasarkan hasil pengujian maka dapat disimpulkan dokumentasi perancangansistem hanya dilakukan pada tahap awal pembangunan yaitu tahap eksplorasi dan tahapperencanaan. Kemudian apabila terjadi perubahan pada saat pembuatan aplikasi, perancangansistem tidak akan diubah, hanya sistem yang sedang dibangun saja yang berubah. Dapatdikatakan bahwa bahwa XP tidak memiliki dokumentasi formal yang dapat digunakan sebagai alat ukur bahwa aplikasi sudah selesai dibangun, namun aplikasi dikatakan selesai apabila klien tidak membutuhkan penambahan requirements pada aplikasi.

Penambahan atau perubahan requirement ini tidak dibatasi, sehingga apapun keinginanklien akan dipenuhi. Hal ini membuat developer harus bisa mengatasi permintaan klien, yangtidak jarang developer menemukan kesulitan untuk mengatasi permintaan tersebut. Kesulitan inidapat berupa kode program yang sulit untuk di temukan untuk mengembangkan sistem, danperubahan data pada tabel database yang mengharuskan developer membangun ulang tabel padadatabase.

\section{SARAN}

Metode XP merupakan metodologi pengembangan perangkat lunak yang tidakmenggunakan dokumentasi formal yang dibuat selama pengembangan. Dokumentasi dilakukanhanya pada tahap awal pengembangan. Apabila ada penambahan atau perubahan requirementsmaka perubahan dapat langsung dilakukan tanpa adanya surat resmi. Untuk itu penulismenyarankan agar pengembang selanjutnya menambahkan satu fase yaitu fasependokumentasian formal tanpa harus menghilangkan aspek agile yang dimiliki oleh XP.

\section{DAFTAR PUSTAKA}

[1] D. Apriadi and A. Y. Saputra, "ECommerce Berbasis Marketplace Dalam Upaya Mempersingkat Distribusi Penjualan Hasil Pertanian," J. Resti, vol. 20, no. 12, pp. 1684-1689, 2016, doi: 
10.3969/j.issn.2095-

4344.2016.12.002.

[2] A. Pratomo, E. Najwaini, A. Irawan, and M. Risa, "Optimasi ECommerce Dengan Penerapan Teknik Seo (Search Engine Optimization) Untuk Meningkatkan Penjualan Pada Ukm Nida Sasirangan," J. IMPACT Implement. Action, vol. 1, no. 1, p. 35, 2019, doi: 10.31961/impact.v1i1.615.

[3] P. Putra, J. Jauhari, P. P. L. Susilo, and A. Meiriza, "Pengembangan Sistem E-Commerce Penjualan Rumah Dengan Pemanfaatan Teknologi Virtual Reality Di Kota Palembang," J. Sist. Inf., vol. 10, no. 1, pp. 1515-1522, 2018.

[4] S. Handayani, "Perancangan Sistem Informasi Penjualan Berbasis ECommerce Studi Kasus Toko Kun Jakarta," Ilk. J. Ilm., vol. 10, no. 2, pp. 182-189, 2018, doi: 10.33096/ilkom.v10i2.310.182-189.

[5] A. U. Hamdani and R. L. Mubarak, "Model E-Commerce Dengan Metode Web Engineering Method Untuk Menunjang pemasaran Produk Pada XYZ Pet Shop," Pros. SENDI_U 2019, no. 1, pp. 978-979, 2019.

[6] A. N. Syahputri and D. A. Anggoro, "Penerapan Sistem Informasi Penjualan Dengan Platform ECOMMERCE Pada Perusahaan Daerah Apotek Sari Husada Demak," SINTECH (Science Inf.
Technol., vol. 3, no. 1, pp. 59-70, 2020.

[7] A. U. Hamdani, "Penjualan Online Berbasis E-Commerce Pada Toko Adhizzshop Dengan Menggunakan Woocommerce," IDEALIS Indones. J. Inf. Syst., vol. 3, no. 1, pp. 26-33, 2020.

[8] R. Rahmi, R. Sari, and R. Suhatman, "Pendekatan Metodologi Extreme Programming pada Aplikasi ECommerce (Studi Kasus Sistem Informasi Penjualan Alat-alat Telekomunikasi)," J. Komput. Terap., vol. 2, no. 2, pp. 83-92, 2016.

[9] D. Susandi and S. Sukisno, "Sistem Penjualan Berbasis E-Commerce Menggunakan Metode Objek Oriented pada Distro Dlapak Street Wear," JSiI (Jurnal Sist. Informasi), vol. 4, pp. 5-8, 2017, doi: 10.30656/jsii.v4i0.368.

[10] F. Purwaningtias, "E-Commerce Penjualan Berbasis Metode Ooad," J. Cendikia, vol. XV, no. April, pp. 1-5, 2018.

[11] A. M. Adi Prsetiya Nanda, "Aplikasi electronic commerce sebagai media penjualan produk makanan ringan business development center kabupaten pringsewu," J. TAM, vol. 9, no. 2013, pp. 127-133, 2018 